\title{
Psicopatologia na contemporaneidade: análise comparativa entre o DSM-IV e o DSM-V ${ }^{\star}$
}

\author{
Alexandre Simões Ribeiro, (DD I, $\star \star$ Gesianni Amaral Gonçalves, (D) I Elizabeth Fátima Teodoro, (D) II \\ Suelen Aparecida Batista, (D) I Pedro Henrique Estevão Ferreira (D) I \\ ${ }^{I}$ Universidade do Estado de Minas Gerais, Divinópolis, MG, Brasil \\ II Universidade Federal de São João del-Rei, Minas Gerais, MG, Brasil
}

\begin{abstract}
Resumo
O DSM (Diagnostic and Statistical Manual of Mental Disorders) é um sistema diagnóstico e estatístico de classificação dos transtornos mentais, segundo o modelo categorial, destinado à prática clínica e à pesquisa em psiquiatria elaborado pela APA (American Psychiatric Association). Esse manual é constantemente revisado e reeditado no intuito de atualizar suas classificações psicodiagnósticas. Nesse sentido, o presente artigo objetivou efetuar uma análise comparativa entre as classes e as categorias diagnósticas dos quadros clínicos referentes às perturbações de ansiedade, às alterações do humor e às perturbações relativas à infância e adolescência vigentes no DSM-IV e no DSM-V, de modo a mapear quais entidades clínicas foram incluídas, excluídas ou fundidas, formando novas classes e categorias diagnósticas na versão mais atualizada do manual. A metodologia utilizada foi a pesquisa bibliográfica e documental de caráter qualitativo, por meio de um estudo descritivo e de uma análise de dados de cunho comparativo. Os resultados referentes à comparação das classes e categorias diagnósticas apontam significativos acréscimos nos três eixos analisados que abrem as portas para se debater as consequências da patologização e medicalização de condições próprias do humano, como a TPM, a tristeza, os comportamentos enérgicos das crianças e os rebeldes dos adolescentes.
\end{abstract}

Palavras-chave: DSM; medicalização; psicodiagnóstico; psicopatologia; sofrimento psíquico.

\section{Psychopathology in contemporary society: comparative analysis of the DSM-IV and DSM-V}

\begin{abstract}
The Diagnostic and Statistical Manual of Mental Disorders (DSM) is a diagnostic and statistical system for classifying mental disorders according to the categorical model for clinical practice and research in psychiatry prepared by the APA (American Psychiatric Association). This manual is constantly revised and reissued to update its psychodiagnostic classifications. In this sense, the present article aimed to make a comparative analysis between the classes and the diagnostic categories of the clinical frameworks related to anxiety disorders, mood alterations and childhood and adolescent disorders in the DSM-IV and DSM-V, to map which clinical entities were included, excluded or merged, forming new diagnostic classes and categories in the most updated version of the manual. The methodology used was qualitative bibliographic and documentary research through a descriptive study and a comparative data analysis. The results regarding the comparison of diagnostic classes and categories point to significant increases in the three analyzed axes that open the doors to debate the consequences of the pathologization and medicalization of human conditions such as PMS, sadness, energetic behavior of children and rebels of teenagers.
\end{abstract}

Keywords: DSM; medicalization; psychodiagnosis; psychopathology; psychic suffering.

\section{Introdução}

Nas últimas décadas, torna-se cada vez mais evidente o conjunto de deslocamentos e transformações pelos quais vem passando a saúde pública brasileira, especialmente o campo da saúde mental (MENDES, 2004; BEZERRA JÚNIOR, 2011). Essas transformações inevitavelmente conduzem os profissionais aí atuantes (psicólogos, psicanalistas, psiquiatras, enfermeiros, assistentes sociais, terapeutas ocupacionais, entre outros) a constantemente repensarem os princípios e os limites de suas intervenções. Trata-se, pois, de uma constante revisita à clínica, às suas possibilidades bem como desafios.

\footnotetext{
^ Programa Interno de Incentivo à Pesquisa e à Extensão (Proinpe) da UEMG - Unidade Acadêmica Divinópolis, 2015-2016. Grupo de pesquisa PESC: Plataforma de Estudo e Pesquisa sobre Subjetividade e Contemporaneidade.

$\star \star$ Endereço para correspondência: Universidade do Estado de Minas Gerais, Unidade acadêmica de Divinópolis. Av. Paraná, 3001 (Campus Universitário) - Belvedere II. Divinópolis, MG - Brasil. CEP: 35500-970. E-mails: alexandresimoes@terra.com.br, gesianni@terra.com.br, elektraliz@yahoo.com.br, suelen.sistema@gmail.com,pedroestevaopsi@gmail.com

Os dados completos dos autores encontram-se ao final do artigo.
}

Dentre as transformações contemporâneas que se dão no campo da saúde mental, é válido ressaltar dois acontecimentos de amplas consequências. O primeiro se refere ao crescente fenômeno usualmente chamado de medicalização da sociedade (AGUIAR, 2004); o segundo, e é precisamente sobre este acontecimento que esta pesquisa se deteve, à tendência, sem precedentes, de se classificar o sofrimento psíquico (KYRILLOS NETO; CALAZANS, 2012), fazendo calar o que do sujeito insiste em denunciar seu estado e posicionamento psíquicos.

Esses fenômenos se entrecruzam, estabelecendo diversas e fecundas relações de retroalimentação perigosas entre si. Isso porque se a indústria psicofarmacológica avança na medida em que novas categorias diagnósticas são propostas e difundidas no tecido social, por outro lado, muitas dessas categorias tendem a ser demarcadas e percebidas por precisamente existir um fármaco, uma gama de princípios ativos que lhe são aplicáveis. Assim, para Kamers (2013, p. 157) “é a produção dos medica- 
mentos que determina a fabricação de diagnósticos". Raciocínio este que encontra uma interessante síntese nas palavras de Jerusalinsky e Frendrik (2011, p. 6):

A ligeireza (e imprecisão) com que as pessoas são transformadas em anormais é diretamente proporcional à velocidade com que a psicofarmacologia e a psiquiatria contemporânea expandiram seu mercado. Não deixa de ser surpreendente que o que foi apresentado como avanço na capacidade de curar tenha levado a ampliar em uma progressão geométrica a quantidade de doentes mentais.

A forte tendência de se classificar o sofrimento psíquico dentro de uma lógica nitidamente taxonômica e com pretensões à exaustão não é inteiramente nova (BERRIOS, 2008). Os empenhos de categorização dos pacientes por meio dos sintomas invariantes, a tendência a se agrupar afecções semelhantes em um mesmo nicho para daí realizar o estabelecimento de tipos e subtipos de quadros clínicos, bem como o diagnóstico diferencial, são estratégias que se confundem com o próprio nascimento e desenvolvimento da psiquiatria, desde o século XVIII (BERCHERIE, 1989; ÁLVAREZ; ESTEBAN; SAVAGNAT, 2004).

Desde este momento fundante, diversas escolas de psiquiatria (tais como as escolas francesa, alemã e anglo-saxônica) se empenharam por categorizar o sofrimento psíquico por meio de inúmeros critérios (especificidade etiológica, desenvolvimento dos sintomas, etc.). Assim, muitas teorias de classificação foram desenvolvidas, cada qual buscando se estabelecer como a mais correta e completa no campo nosográfico. Sobre esse contexto, Oliveira (apud AMARANTE, 1996, p. 59) expõe que "os 200 anos de psiquiatria que então transcorrem se restringem, a rigor e em síntese, a 200 anos de intermináveis discussões nosográficas, nas quais sistemas classificatórios se contrapõem a outros sistemas classificatórios".

Entretanto, vale ressaltar que a classificação em si não se coloca como um mal no campo científico, uma vez que se apresenta como extremamente necessária a fim de se estudar e conhecer mais profundamente os objetos de pesquisa. No campo clínico, essa lógica não se diferencia, posto que a classificação diagnóstica possibilita ao profissional mapear os sintomas para traçar as possíveis formas de intervenção. Nesse sentido, o diagnóstico assume status de uma importante ferramenta (DALGALARRONDO, 2008).

Todavia, assim que o DSM (Diagnostic and Statistical Manual of Mental Disorders) foi estabelecido, sob os cuidados da APA (American Psychiatric Association), estas classificações ganharam proporções e consequências inéditas ao deixar de serem ferramentas de auxílio clínico para se tornarem uma forma de intervenção hegemônica. Notemos que esses atributos não se restringiram às searas técnicas da psiquiatria e do discurso psicopatológico, visto que, em suas dinâmicas, modificaram diversos aspectos do campo da saúde mental e, por extensão, influenciaram o olhar da sociedade em relação ao sofrimento psíquico e os destinos que lhe são dados.

Fractal, Rev. Psicol., v. 32 - n. 1, p. 46-56, 2020
Nesse sentido, questões atuais como o uso de nomenclaturas diagnósticas feito pela população tal como rótulos estanques do mal-estar e do sofrimento psíquico, assim como o excesso do uso de psicofármacos com o intuito de se extirpar tal sofrimento, interferem no processo de construção das subjetividades, como nos salienta Caponi (2012, p. 119), situação que aponta para o desenvolvimento de uma biopolítica do sofrimento psíquico que:

[...] aparece com um modo de exercer o governo sobre os outros que se vale de critérios pretensamente científicos e validados de classificação e que privilegia um modo de intervenção: a terapêutica farmacológica. Esse dispositivo exclui as narrativas dos sujeitos e suas histórias de vida ou as subordina a explicações biológicas referidas a alterações ou déficit nos neurotransmissores.

Nesses termos, indicadores como os apontados por Silva e Iguti (2013), que atribuem aos ansiolíticos o status de substância controlada mais consumida pela população brasileira no período de 2007 a 2010, assim como o aumento de $44,8 \%$ no consumo de antidepressivos entre 2005 e 2009 , evidenciam que os diagnósticos de transtornos relacionados à ansiedade e à depressão têm sido utilizados com frequência, a ponto inclusive de serem considerados um problema de saúde pública no país, como afirma Lannes (2018). Além disso, em 2013 o clonazepam (fartamente utilizado no tratamento de transtornos da ansiedade e do humor) aparecia em nono lugar entre todos os medicamentos mais vendidos do país (BRASIL, 2013).

Ainda no âmbito dos indicadores, é importante mencionar a venda de metilfenidato, medicamento canonicamente prescrito para o TDA/H (Transtorno do Déficit de Atenção/Hiperatividade), que entre 2004 e 2008 apresentou um aumento de $930 \%$, em consonância com Resende (2014). Na companhia dessa autora, podemos notar também que essa prevalência das prescrições e do uso de psicotrópicos no Brasil se deve à parceria direta entre a clínica psiquiátrica que perpassa as diversas edições do DSM e a indústria farmacológica. Para Couto e Castro (2015, p. 145), "o TDA/H tomou ares de epidemia, sendo classificado como um dos transtornos neurológicos do comportamento que mais atinge crianças em todo o mundo". No Brasil, os dados do Boletim de Farmacoepidemiologia do Sistema Nacional de Gerenciamento de Produtos Controlados (SNGPC), divulgado pela ANVISA (BRASIL, 2012), aponta um aumento de $74,8 \%$ das vendas do cloridrato de metilfenidato nos anos de 2009 e 2011, prescrito para crianças e adolescentes de 6 a 16 anos.

Lannes (2018) também ressalta o aumento de diagnósticos de ansiedade e depressão em crianças e adolescentes e como tratamentos inadequados para essa faixa etária podem resultar inclusive em suicídio por parte dos mesmos. Com efeito, a autora acredita que, "embora a depressão na infância seja algo consideravelmente novo, já foi capaz de se tornar um problema de saúde pública em pouco tempo" (p. 46). Não sem razão, têm se tornado cada vez mais importantes as pesquisas sobre a patologização e medicalização infantil, como afirma Luengo (2010). 
Diante desses pressupostos, o estudo do DSM, do mesmo modo que a compreensão das mudanças propostas pela última versão desse manual, torna-se essencial para o conhecimento da classificação das psicopatologias que vêm sendo adotadas na contemporaneidade pelos profissionais da saúde mental e aceitas, de modo irrestrito, pela população. Nesse sentido, questiona-se: quais foram as modificações referentes aos critérios diagnósticos e categorias clínicas das perturbações de ansiedade, humor e às relativas à infância e adolescência ocorridas na passagem do DSM-IV para o DSM-V?

Buscando responder a essa questão, a investigação objetivou efetuar uma análise comparativa entre as classes e as categorias diagnósticas dos quadros clínicos referentes às perturbações de ansiedade, às alterações do humor e às perturbações relativas à infância e adolescência vigentes no DSM-IV e no DSM-V, de modo a mapear quais entidades clínicas foram incluídas, excluídas ou fundidas, formando novas classes e categorias diagnósticas na versão mais atualizada do manual (lançada em 18 de maio de 2013). Conforme Magalhães (2001, p. 35), “a psicofarmacologia [assim como a classificação] é simultaneamente um fato da clínica, da ciência, da epistemologia, da ideologia, da mídia, da economia, da metafísica e da ética". Portanto, investigá-la é uma tentativa de revelar que tipo de subjetividade a sociedade contemporânea vem forjando, como aponta Moretto (2015).

\section{A lógica taxonômica do DSM: classificando o sofrimento psíquico}

O DSM foi traduzido para a língua portuguesa como Manual Diagnóstico e Estatístico de Transtornos Mentais. Esse compêndio psicopatológico é regularmente organizado, revisto e editado pela APA, tendo como principal função servir de "instrumento que auxilia as pesquisas clínicas e teóricas no campo da saúde mental" (CATANI, 2014, p. 23). Assim, por meio de um breve resgate histórico dessas construções, verifica-se que, em sua primeira edição, publicada em 1952, o DSM se baseava em uma compreensão psicossocial da doença mental, na qual o uso de terminologias como "mecanismos de defesa", "neurose" e "conflito neurótico" evidenciavam uma leitura psicanalítica dos fenômenos psicopatológicos. Nesse primeiro momento, o manual era composto de 106 categorias de doenças mentais (DUNKER; KYRILLOS NETO, 2011).

A segunda versão foi publicada em 1968 e continha 182 categorias diagnósticas. Sua construção surgiu em meio a Guerra do Vietnã e, devido a uma clara necessidade empírica oriunda da época, nota-se uma grande influência da teoria comportamental em detrimento da concepção biopsicossocial dos transtornos mentais utilizada até então. Ainda assim, o modo psicanalítico de compreensão permaneceu vigente na disposição do profissional da saúde mental de escutar o sujeito em sofrimento, posto que ainda era a principal forma de traçar qualquer diagnóstico (RESENDE, 2014). Martinhago e Caponi (2019) chamam a atenção para o fato de que, no final da década de 1970, identificaram-se divergências psicodiagnósticas entre os psiquiatras estadunidenses e os europeus. Essa percepção levou à elaboração de uma nova versão do manual que buscava a padronização e universalização dos diagnósticos psiquiátricos.

Nesse fio histórico, em 1980 o DSM-III foi publicado. Nessa versão, porém, as noções da psicanálise cederam espaço ao novo paradigma da ciência, pautado em critérios da medicina baseada em evidências (DUNKER, 2014). Esse fato foi considerado uma revolução científica, de modo que a terceira versão do manual "foi o marco da mudança de paradigma da psiquiatria, que até o momento era regida predominantemente pela psicanálise" (MARTINHAGO; CAPONI, 2019, p. 2). Com efeito, o número de categorias diagnósticas saltou para 265. Além da extinção da classe de psicopatologias denominada de neurose, visando "não suscitar questões etiológicas e, assim, a expressão doença mental passa a ser substituída por transtorno mental" (RESENDE, 2014, p. 20).

Por volta de 1987, essa terceira edição foi revisada e ampliada, de modo que o número de categorias diagnósticas se ampliou para 292, consagrando a nomenclatura "transtorno", doravante alastrada. Diante desse contexto, torna-se claro que a escuta do sujeito passou a ser considerada desnecessária, uma vez que o saber que ele tem de si próprio já não influenciava o diagnóstico (RESENDE, 2014).

Conforme Martinhago e Caponi (2019), em 1994 foi lançado o DSM-IV, contando com 297 categorias, o qual, por sua vez, foi revisado em 2000, mas sem grandes acréscimos. Esses psicodiagnósticos foram organizados em cinco eixos distribuídos em 886 páginas. Na concepção dos autores acima citados, a principal mudança dessa versão "foi a inclusão de um critério de significância clínica para praticamente metade das categorias que tinham sintomas e causavam sofrimento clinicamente importante ou prejuízo no funcionamento social ou ocupacional, entre outras áreas" (p. 3). Nesse momento, apagou-se todo vestígio de etiologia e instaurou-se decididamente o modelo nosográfico de diagnóstico. Desse modo, "o manual passa a ser visto como um método infalível que, após o preenchimento de um 'checklist', fornece automaticamente um diagnóstico psiquiátrico" (RESENDE, 2014, p. 24).

A última versão do DSM, como já salientamos, foi publicada em 2013. Para Resende (2014, p. 24), a aposta agora é no "diagnóstico dimensional, que englobaria o sujeito por completo". Martinhago e Caponi (2019, p. 3) descrevem essa quinta edição do manual do seguinte modo:

[...] fundamentada no modelo categorial organizado em três sessões, totalizando 947 páginas. A seção I apresenta as orientações para o uso clínico e forense. A seção II descreve os critérios e códigos diagnósticos dos transtornos. E, por último, na seção III estão os instrumentos para as avaliações dos sintomas, os critérios sobre a formulação cultural dos transtornos, o modelo alternativo para os transtornos de personalidade e uma descrição das condições clínicas para estudos posteriores.

Verifica-se, pois, que a tarefa classificatória se tornou o escopo central da psicopatologia praticada a partir do DSM-V, que, na contemporaneidade, figura como o representante do discurso biologizante, no qual se subs- 
tituem “[...] as grandes categorias (neurose, psicose, esquizofrenia) por descrições especificadas de fenômenos objetivos, trazendo um empobrecimento à lógica diagnóstica, pois se privilegia a descrição dos sintomas ao invés da patologia” (KYRILLOS NETO et al., 2011, p. 47). Quanto a isso, cumpre observar que a lógica da qual a psicanálise parte para analisar o sofrimento se apresenta como uma proposição irredutível ao proposto pela dinâmica manualista do DSM, posto que intenta não desconsiderar os aspectos que emergem particulares, e mesmo singulares, do sintoma do sujeito, reconhecendo com isso os limites da lógica da classificação, no ponto em que, ao operar com a consecução de uma lógica do real do sofrimento, a psicanálise passa a evidenciar os limites de escrita da própria ciência (SILVA, 2019), que progride em seu afã de tudo classificar. Desse modo, principalmente no DSM-V, os distúrbios "falam" pelo paciente, ou seja, o saber do manual diagnóstico se sobrepõe a toda tentativa do paciente de se posicionar como sujeito. Nesse sentido, há um viés de desresponsabilização do mesmo diante da patologia, que passa a ter causa totalmente biológica, elevando ao zênite o Organicismo, tal qual preconizado por Griesinger no século XIX (SIMÕES, 2019).

Mário Goldenberg (2012, apud RESENDE, 2014, p. 10) afirma que a nova versão do DSM tem efeitos nefastos na cultura contemporânea, uma vez que se apresenta como uma imposição para patologizar e medicalizar a comunidade por meio de uma reformulação classificatória que amplia o discurso da ciência sobre as doenças mentais, dando-lhe força maior para distinguir o normal do patológico: "Ou seja, tenta, sob um disfarce de termos científicos, uma classificação do inclassificável: o padecimento".

As alterações do DSM, transcorridas ao longo da segunda metade do século XX, findam sempre, na ampliação das categorias diagnósticas presentes neste manual. Por ser um compêndio construído, a princípio, de forma ateórica, ele estaria acima de todas as distintas perspectivas teóricas existentes entre os mais diferentes profissionais atuantes na saúde mental. Porém, a diferença de concepção acerca do sofrimento psíquico existente no repertório teórico de áreas como a psicanálise, que parte da premissa do inconsciente (e, portanto, de um intangível atrelado ao humano), e a psiquiatria contemporânea, que enxerga no sofrimento uma doença fundada em um desequilíbrio dos neurotransmissores, torna tais perspectivas epistemológicas usualmente inconciliáveis, ainda que isto não impeça, necessariamente, a possibilidade de comunicação entre estes distintos saberes (ALBERTI; FIGUEIREDO, 2006). Sobre essas diferenças epistemológicas Resende (2014, p. 13) esclarece que

A psiquiatria do DSM e a psicanálise partem do sintoma. Entretanto, esse ponto é, hoje em dia, o único de convergência entre as práticas. A psiquiatria busca a eliminação do sintoma, uma normalização psicossocial do sujeito, a adaptação deste à sociedade e a sua moral civilizatória por considerar o sintoma como um desvio, uma perturbação na ordem pública, em suma, um índice de um transtorno. Para a psicanálise, o sintoma apresenta dois aspectos: disfunção e sofrimento. No entanto, só há recomendação de análise quando há sofrimento. A psicanálise não se pauta na eliminação de sintoma e sim na transmutação de sintoma. Quando um sintoma é eliminado sem entender sua função para o sujeito, outro toma seu lugar, seja em maior ou menor sintonia com o desejo do sujeito. Nesse sentido, a psicanálise não direciona o tratamento exclusivamente para a cura tida como eliminação de todos os sintomas, já que o chamado sujeito é, para a teoria psicanalítica, apenas aquele que está em sintonia com seu sintoma.

De antemão, nota-se que, com o advento do DSM-V e a consolidação da nomeação em série e em larga escala do sofrimento psíquico, a saúde mental assume um novo contorno no cenário atual, uma vez que se instala, de modo significativo, um processo de patologização da existência que culmina com a chamada medicalização da vida, na qual qualquer desvio da ordem estipulada socialmente se torna passível de medicação (RESENDE, 2014). Por essa perspectiva, "o conceito de transtorno ignora toda a história da psicopatologia e rompe de vez com as escolas de pensamento, principalmente com a psicanálise, em uma tentativa de ignorar o sujeito" (RESENDE, p. 12-13). Pois, como assevera Dunker (2012, p. 35), a novidade da psicanálise reside justamente em considerar e incluir "o diagnóstico pré-constituído, dado pelo próprio paciente". Isso porque, muitas vezes, o processo clínico passa pela desconstrução psicodiagnóstica advinda dos âmbitos: educacional, familiar, trabalhista, médico, estético, dentre outros, no sentido de deslegitimar "o discurso social da necessidade de uma supressão do pathos, ou seja, daquilo que, em psicanálise, traceja os caminhos possíveis de um tratamento" (TEODORO, 2019, p. 139).

\section{Metodologia}

A presente pesquisa contempla os métodos de pesquisa bibliográfica e documental. Bibliográfica, no ponto em que recorre a referenciais teóricos já publicados em livros, artigos e teses de modo a conferir um amplo acesso a análises já desenvolvidas do assunto trabalhado (LAKATOS; MARCONI, 2001). Documental direta, por se basear em dois documentos oficiais e, consequentemente, de fontes primárias (DSM-IV e V), elaborados pela APA, materiais cujo tratamento analítico recebido não esgota outras perspectivas investigativas (GIL, 2008) como as encontradas neste estudo.

Os procedimentos, quanto aos objetivos, foram delineados pela pesquisa descritiva, uma vez que ela se preocupa com a descrição das características de um determinado grupo, como as categorias psicodiagnósticas, possibilitando ainda o estabelecimento de relações entre suas variáveis (GIL, 2008). Quanto à metodologia empregada na abordagem do problema, a pesquisa se assinala como qualitativa, por não apresentar dados quantificáveis, mas envolver diretamente uma perspectiva interpretativa (LAKATOS; MARCONI, 2001). Por fim, utilizou-se o método comparativo, que "procede pela investigação de indivíduos, classes, fenômenos ou fatos, com vistas a ressaltar as diferenças e similaridades entre eles" (GIL, 2008, p. 16). 
Foram selecionados três eixos a serem analisados: I) Perturbações de Ansiedade; II) Alterações do humor (cíclicas, tais como Transtorno Afetivo Bipolar, e não-cíclicas, tais como Depressões); e III) Perturbações relativas à infância e à adolescência (transtornos que buscam categorizar as dificuldades de aprendizagem, indisciplinas, alterações do desenvolvimento, etc.). O recorte desses eixos se deve à percepção dos altos índices na taxa da medicalização e, consequentemente, dos psicodiagnósticos no âmbito de psicopatologias que envolvem, principalmente, a ansiedade e o humor, assim como o fenômeno cada vez mais crescente da medicalização infantil. Essas percepções, invariavelmente, apontam para um problema de saúde pública generalizado, que tem em seu núcleo o excesso de psicodiagnósticos.

Para análise e interpretação dos dados foram construídos extensos quadros comparativos sobre as referidas classes diagnósticas (Transtorno de Ansiedade, Transtorno de Humor e Transtornos relativos à infância e à adolescência) e suas categorias no DSM-IV e V. Em seguida, foram identificadas as semelhanças e diferenças entre elas, salientando acréscimos, deslocamentos e exclusões.

\section{Resultados e Discussão}

\section{Análise comparativa das classes diagnósticas}

Após a análise comparativa entre o DSM-IV e o DS$\mathrm{M}-\mathrm{V}$ das classes diagnósticas das Alterações de Ansiedade, Alterações de Humor e Alterações relativas à infância e adolescência, foram verificadas algumas modificações importantes, como se verifica na Tabela 1 .
Essas modificações referentes às classes diagnósticas evidenciam uma ampliação diagnóstica significativa, tanto no que concerne às perturbações da ansiedade quanto do humor, posto que ambas originam duas novas classes. Assim, não se torna incomum dados como os apresentados pela Organização Mundial de Saúde (OMS), nos quais a prevalência mundial do transtorno de ansiedade (TA) é de 3,6\%. No Brasil, mostra-se ainda mais alarmante, posto que o TA aparece em $9,3 \%$ da população (são mais de 18,6 milhões de brasileiros), possuindo o maior número de casos de ansiedade entre todos os países do mundo, como aponta Fernandes et al. (2018). Com a depressão, a situação não se mostra muito diferente, uma vez que o Relatório global lançado pela OMS aponta que o número de casos de depressão aumentou $18 \%$ entre 2005 e 2015: são 322 milhões de pessoas em todo o mundo, a maioria mulheres. No Brasil, a depressão atinge 5,8\% da população, são 11,5 milhões de pessoas (NAÇÕES UNIDAS, 2017, online).

Todos esses dados nos levam a questionar: em que medida o aumento dos casos está relacionado aos deslocamentos registrados no DSM-V? Martinhago e Caponi (2019, p. 11/15) refletem sobre essa questão ressaltando "as conveniências que os DSMs geram para potências como as indústrias farmacêuticas, conjuntamente com as seguradoras de saúde e a classe médica", uma vez que "facilita a burocracia dos seguros de saúde, amplia o mercado para profissionais da saúde, aumenta significativamente o número de diagnósticos de transtornos mentais e, consequentemente, o consumo de medicamentos,

Tabela 1 - Análise comparativa entre o DSM-IV e o DSM-V quanto às classes diagnósticas:

$\begin{aligned} & \text { Perturbações de Ansiedade e } \\ & \text { Transtornos Relacionados }\end{aligned}$
$\begin{array}{lll}\text { Perturbações do Humor } & \text { - Transtorno Obsessivo-compulsivo e Transtornos } \\ \text { Relacionados. } & \text { Transtorno Relacionado a Trauma e Estressores; } \\ & \text { - Transtorno Bipolar e Transtornos } & \text { Relacionados; } \\ \text { - Transtorno Depressivo. }\end{array}$

Perturbações que aparecem habitualmente na primeira e na segunda infâncias ou na adolescência

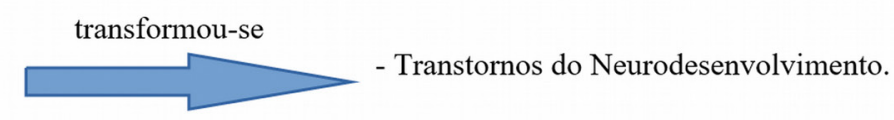

Salienta-se que a classe diagnóstica nomeada de Perturbações de Ansiedade do DSM-IV permaneceu no DS$\mathrm{M}-\mathrm{V}$, além de originar mais duas novas classes, são elas: Transtorno Obsessivo-compulsivo e Transtornos Relacionados e Transtorno Relacionado a Trauma e a Estressores. Por outro lado, a classe diagnóstica denominada Perturbações do Humor, no DSM-IV, foi excluída do DSM-V, porém transformou-se também em duas novas classes diagnósticas do DSM-V: Transtorno Bipolar e Transtornos Relacionados e Transtorno Depressivo. Por fim, a classe diagnóstica Perturbações que aparecem habitualmente na primeira e na segunda infâncias ou na adolescência também foi excluída do DSM-IV, transformando-se, no DS$\mathrm{M}-\mathrm{V}$, em: Transtornos do Neurodesenvolvimento. entre muitos outros aspectos". Nesse conseguinte, não se torna difícil compreender o porquê de estes manuais se transformarem em hegemônicos na contemporaneidade. 
Análise comparativa das categorias diagnósticas

Quadro 1"- Análise comparativa entre o DSM-IV e o DSM-V quanto às categorias que foram acrescidas, excluídas ou deslocadas

\begin{tabular}{|c|c|c|}
\hline \multirow{2}{*}{$\begin{array}{c}\text { Classe } \\
\text { diagnóstica }\end{array}$} & \multicolumn{2}{|c|}{ Categorias } \\
\hline & DSM-IV & DSM-V \\
\hline $\begin{array}{l}\text { Transtornos } \\
\text { de Ansiedade }\end{array}$ & $\begin{array}{l}\text { Perturbação do pânico sem agorafobia; Perturbação do } \\
\text { pânico com agorafobia; Agorafobia sem história de } \\
\text { perturbação do pânico; Fobia específica; Fobia social; } \\
\text { Perturbação obsessivo-compulsivo (deslocada para } \\
\text { uma classe diagnóstica denominada Transtorno } \\
\text { Obsessivo-Compulsivo e Transtornos relacionados); } \\
\text { Perturbação de estresse pós-traumático (deslocada para } \\
\text { uma nova classe diagnóstica denominada Transtornos } \\
\text { relacionados a traumas e a estressores); Perturbação de } \\
\text { estresse agudo (deslocada para uma nova classe } \\
\text { diagnóstica denominada Transtornos relacionados a } \\
\text { traumas e a estressores); Perturbação de Ansiedade } \\
\text { Generalizada (TAG); Perturbação de Ansiedade devido } \\
\text { à condição médica; Perturbação de Ansiedade induzida } \\
\text { por substância. }\end{array}$ & $\begin{array}{l}\text { Transtorno de Ansiedade de separação (acrescida); } \\
\text { Mutismo seletivo (acrescida); Fobia específica; } \\
\text { Transtorno de Ansiedade Social (Fobia Social); } \\
\text { Transtorno de Pânico; Agorafobia; Transtorno de } \\
\text { Ansiedade Generalizada (TAG); Transtorno de } \\
\text { Ansiedade Induzido por Substância/Medicamento; } \\
\text { Transtorno de Ansiedade Devido a Outra Condição } \\
\text { Médica; Outro Transtorno de Ansiedade } \\
\text { Especificado (acrescida); Transtorno de Ansiedade } \\
\text { Não Especificado (acrescida). }\end{array}$ \\
\hline $\begin{array}{l}\text { Transtorno } \\
\text { Obsessivo- } \\
\text { compulsivo e } \\
\text { Transtornos } \\
\text { Relacionados }\end{array}$ & $\begin{array}{l}\text { Não existia enquanto Classe diagnóstica, configurava- } \\
\text { se como categoria clínica do Transtorno de Ansiedade. }\end{array}$ & $\begin{array}{l}\text { Transtorno } \begin{array}{l}\text { Obsessivo-compulsivo; } \\
\text { Transtorno }\end{array} \\
\begin{array}{l}\text { Dismórfico Corporal (acrescida); } \\
\text { Acumstorno de }\end{array} \\
\text { Acumulação } \begin{array}{c}\text { Transtorida); Tricotilomania } \\
\text { (Transtorno de Arrancar o Cabelo) (acrescida); }\end{array} \\
\text { Transtorno de Escoriação (Skin-picking) } \\
\text { (acrescida); Transtorno Obsessivo-compulsivo e } \\
\text { Transtorno Relacionado Induzido por } \\
\text { Substância/Medicamento (acrescida); Transtorno } \\
\text { Obsessivo-compulsivo e Transtorno Relacionado } \\
\text { Devido a Outra Condição Médica (acrescida); } \\
\text { Outro Transtorno Obsessivo-compulsivo e } \\
\text { Transtorno Relacionado Especificado (acrescida); } \\
\text { Transtorno Obsessivo-compulsivo e Transtorno } \\
\text { Relacionado Não Especificado (acrescida). }\end{array}$ \\
\hline $\begin{array}{l}\text { Transtornos } \\
\text { Relacionados } \\
\text { a Trauma e a } \\
\text { Estressores }\end{array}$ & $\begin{array}{l}\text { Não existia enquanto Classe diagnóstica, configurava- } \\
\text { se como categoria clínica do Transtorno de Ansiedade. }\end{array}$ & 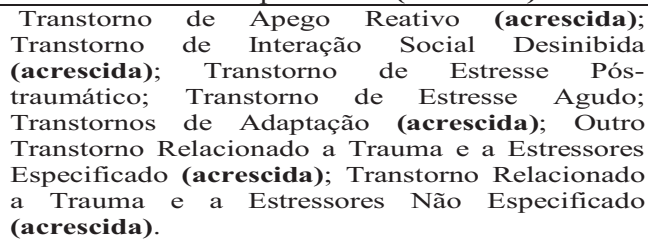 \\
\hline $\begin{array}{l}\text { Transtornos } \\
\text { do Humor }\end{array}$ & $\begin{array}{l}\text { Episódio Depressivo Maior (deslocada para critério } \\
\text { diagnóstico da categoria dos Transtornos Bipolares); } \\
\text { Episódio Maníaco (deslocada para critério diagnóstico } \\
\text { da categoria dos Transtornos Bipolares); Episódio } \\
\text { Misto (deslocada para critério diagnóstico da categoria } \\
\text { dos Transtornos Bipolares); Episódio hipomaníaco } \\
\text { (deslocada para critério diagnóstico da categoria dos } \\
\text { Transtornos Bipolares); Perturbação Depressiva Major } \\
\text { (deslocada para uma nova classe diagnóstica } \\
\text { denominada Transtornos Depressivos); Distimia } \\
\text { (deslocada para uma nova classe diagnóstica } \\
\text { denominada Transtornos Depressivos); Perturbação } \\
\text { Depressiva Sem Outra Especificação (deslocada para } \\
\text { uma nova classe diagnóstica denominada Transtornos } \\
\text { Depressivos); Perturbação Bipolar I (deslocada para } \\
\text { uma classe diagnóstica denominada: Transtorno Bipolar } \\
\text { e Transtornos Relacionados); Perturbação Bipolar II } \\
\text { (deslocada para uma classe diagnóstica denominada: } \\
\text { Transtorno Bipolar e Transtornos Relacionados); } \\
\text { Perturbação Ciclotímico (deslocada para uma classe } \\
\text { diagnóstica denominada: Transtorno Bipolar e } \\
\text { Transtornos Relacionados); Perturbação do Humor } \\
\text { devido a outra condição física (excluída do DSM-V); } \\
\text { Perturbação do Humor Induzida por Substâncias } \\
\text { (excluída do DSM-V); Perturbação do Humor Sem } \\
\text { Outra Especificação (excluída do DSM-V). }\end{array}$ & $\begin{array}{l}\text { Classe diagnóstica excluída, passando a configurar } \\
\text { duas novas classes diagnósticas: Transtorno } \\
\text { Bipolar e Transtornos Relacionados; Transtornos } \\
\text { Depressivos. }\end{array}$ \\
\hline $\begin{array}{l}\text { Transtorno } \\
\text { Bipolar e } \\
\text { Transtornos } \\
\text { Relacionados }\end{array}$ & $\begin{array}{l}\text { Não existia enquanto Classe diagnóstica, configurava- } \\
\text { se como categoria clínica do Transtorno de Humor. }\end{array}$ & $\begin{array}{l}\text { Transtorno Bipolar Tipo I; Transtorno Bipolar Tipo } \\
\text { II; Transtorno Ciclotímico; Transtorno Bipolar e } \\
\text { Transtorno Relacionado Induzido por } \\
\text { Substância/Medicamento (acrescida); Transtorno } \\
\text { Bipolar e Transtorno Relacionado Devido a Outra } \\
\text { Condição Médica (acrescida); Outro Transtorno } \\
\text { Bipolar e Transtorno Relacionado Especificado } \\
\text { (acrescida); Transtorno Bipolar e Transtorno } \\
\text { Relacionado Não Especificado (acrescida). }\end{array}$ \\
\hline
\end{tabular}

* Todas as modificações se encontram destacadas para melhor visualização. 
Continuação

\begin{tabular}{|c|c|c|}
\hline \multirow{2}{*}{$\begin{array}{l}\text { Classe } \\
\text { diagnóstica }\end{array}$} & \multicolumn{2}{|c|}{ Categorias } \\
\hline & DSM-IV & DSM-V \\
\hline $\begin{array}{l}\text { Transtornos } \\
\text { Depressivos }\end{array}$ & $\begin{array}{l}\text { Não existia enquanto Classe diagnóstica, configurava- } \\
\text { se como categoria clínica do Transtorno de Humor. }\end{array}$ & 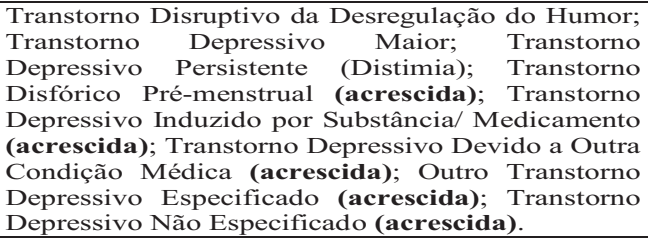 \\
\hline $\begin{array}{l}\text { Transtornos } \\
\text { geralmente } \\
\text { diagnosticad } \\
\text { os pela } \\
\text { primeira vez } \\
\text { na infância } \\
\text { ou } \\
\text { adolescência }\end{array}$ & $\begin{array}{l}\text { Deficiência Mental (excluída do DSM-V; Perturbações } \\
\text { da Aprendizagem (deslocada para Transtorno } \\
\text { Específico da Aprendizagem); Perturbações das } \\
\text { aptidões motoras (deslocada para Transtornos } \\
\text { Motores); Perturbações da comunicação; Perturbações } \\
\text { globais do desenvolvimento (excluída do DSM-V); } \\
\text { Perturbações Disruptivas do Comportamento e de } \\
\text { Déficit de Atenção (desmembrada); Perturbações da } \\
\text { alimentação e do comportamento alimentar da primeira } \\
\text { infância ou do início da segunda infância (excluída do } \\
\text { DSM-V); Perturbação de Tique (deslocada para a } \\
\text { subcategoria dos Transtornos Motores); Perturbações da } \\
\text { Eliminação (excluída do DSM-V); Outras perturbações } \\
\text { da primeira e segunda infâncias (excluída do DSM-V). }\end{array}$ & $\begin{array}{l}\text { Classe diagnóstica excluída, passando a configurar } \\
\text { a classe dos Transtornos do Neurodesenvolvimento }\end{array}$ \\
\hline $\begin{array}{l}\text { Transtornos } \\
\text { do } \\
\text { Neurodesen- } \\
\text { volvimento }\end{array}$ & Não existia enquanto Classe diagnóstica. & $\begin{array}{l}\text { Deficiências Intelectuais (acrescida); Transtornos } \\
\text { da Comunicação; Transtorno do Espectro Autista } \\
\text { (deslocada das Perturbações globais do } \\
\text { desenvolvimento do DSM-IV); Transtorno de } \\
\text { Déficit de Atenção/Hiperatividade (deslocada das } \\
\text { Perturbações Disruptivas do Comportamento e de } \\
\text { Déficit de Atenção do DSM-IV); Transtorno } \\
\text { Específico da Aprendizagem (deslocada das } \\
\text { Perturbações da Aprendizagem); Transtornos } \\
\text { Motores (deslocada das Perturbações das aptidões } \\
\text { motoras do DSM-IV); Outros Transtornos do } \\
\text { Neurodesenvolvimento (acrescida). }\end{array}$ \\
\hline
\end{tabular}

O Quadro 1 se refere à comparação das categorias diagnósticas do DSM-IV e do DSM-V. Analisou-se inicialmente a classe de psicopatologias referentes às Alterações de Ansiedade, que no DSM-IV era composta por 11 categorias de transtornos e que no DSM-V, apesar de ter sido mantida, sofreu algumas alterações. Dentre elas, destaca-se que as duas categorias, não existentes anteriormente, foram acrescidas: Outro Transtorno de Ansiedade Especificado e o Transtorno de Ansiedade Não Especificado. Já o Transtorno de Ansiedade de Separação e o Mutismo Seletivo foram deslocados da extinta classe diagnóstica denominada Transtornos Geralmente Diagnosticados pela Primeira Vez na Infância ou na Adolescência, passando a compor os Transtornos de Ansiedade. Nesse sentido, constatou-se que a classe diagnóstica Transtornos de Ansiedade permanece no DSM-V com 11 categorias, das quais duas são novas.

Sobre a categoria Perturbação Obsessivo-compulsiva, que no DSM-IV compunha um quadro diagnóstico da classe do Transtorno de Ansiedade, no DSM-V assume status de uma nova classe, denominada Transtornos Obsessivo-Compulsivos e outros Transtornos Relacionados. Nessa nova classe, verifica-se o acréscimo de oito novas categorias de transtornos, dentre os quais se destacam: Transtorno Dismórfico Corporal; Transtorno de Acumulação; Tricotilomania (Transtorno de Arrancar o Cabelo) e Transtorno de Escoriação (Skin-picking). Desta forma, essa classe conta com nove categorias, configurando oito novas categorias em relação ao DSM-IV.

Ainda pertencentes à classe de Transtornos de Ansiedade do DSM-IV, a Perturbação de Estresse Pós-traumático e a Perturbação de Estresse Agudo também se configuram como uma nova classe diagnóstica no DSM-V - Transtornos Relacionados a Traumas e a Es- tressores. Tal classe foi acrescida de cinco categorias, destacando-se: Transtorno de Apego Reativo; Transtorno de Interação Social Desinibida e Transtornos de Adaptação. Assim, essa nova classe diagnóstica totaliza a descrição de sete categorias de transtornos. Esses dados permitem constatar que o que era, inicialmente, uma classe diagnóstica desdobrou-se, no DSM-IV, em três classes distintas na nova versão do manual, totalizando 27 categorias, das quais quinze são novas.

A segunda análise apresentada no Quadro 1 se refere às Alterações do Humor, que no DSM-IV aparece sob a égide de Perturbações do Humor. Essa classe deixa de existir no DSM-V, de modo que as treze categorias de transtornos que a compunham foram deslocadas (10 delas para novas classes), enquanto outras três foram excluídas da nova versão do manual. Além disso, três categorias referentes aos transtornos bipolares presentes no DSM-IV, no quadro de Transtornos de Humor, foram deslocados, no DSM-V, para uma classe específica, denominada Transtorno Bipolar e Transtornos Relacionados. Junto a esses deslocamentos, verifica-se o acréscimo de quatro novas categorias. Nessa nova classe, soma-se, então, o total de sete transtornos no DSM-V.

A legitimação do transtorno bipolar enquanto uma classe diagnóstica e o "afrouxamento dos limites do diagnóstico geraram uma expansão colossal do mercado farmacêutico e lançaram um convite generalizado a que os consumidores se vissem como bipolares" (LEADER, 2015, p. 12). Não sem razão, na concepção do autor, as taxas da doença subiram de menos de $4 \%$ da população para quase $25 \%$ dos norte-americanos. Esse aumento faz indagar em que medida a bipolaridade é uma construção mercadológica, como faz crer o autor supracitado, uma vez que essa oscilação frenética de humores parece muito 
bem combinar com os ritmos estranhos e convulsivos da vida na sociedade contemporânea, caracterizada por uma fluidez que evanesce no instante do momento, mas que exige marca constante das imagens performáticas.

Também proveniente dos Transtornos do Humor do DSM-IV, o Transtorno Disruptivo da Desregulação do Humor, Transtorno Depressivo Maior e Transtorno Depressivo Persistente (Distimia) foram deslocados para uma nova classe do DSM-V, denominada de Transtornos Depressivos. A essa classe foram acrescentadas cinco categorias, totalizando oito categorias de transtornos. Dessas, chama a atenção o Transtorno Disfórico Pré-menstrual, que comumente é conhecido como TPM (tensão pré-menstrual) e que causou considerável polêmica, uma vez que muitos estudiosos e profissionais da saúde mental acreditavam que transformar um sintoma comum do ser mulher em categoria diagnóstica significava nomear como psicopatologia essa condição do corpo feminino. Nomeação essa que aponta para o que Vieira (2003) descreve como a medicalização do corpo feminino.

É fato que essa medicalização do ser mulher não é recente na história da humanidade; na Grécia antiga já se buscava tratamento para os deslocamentos do feminino que chamavam de histeria, posteriormente, houve o controle da reprodução por meio de anticoncepcionais e, atualmente, a elevação da TPM a uma categoria diagnóstica e, consequentemente, medicalização de um acontecimento que se repete ao longo da vida com maior ou menor intensidade. São situações que geram questionamentos: qual o propósito de se medicalizar o corpo feminino? A quem serve tal medicalização?

Retomando a análise dos Transtornos do Humor, foram identificados, em um quadro geral, que o que era representado no DSM-IV por uma classe diagnóstica Transtornos do Humor - e suas treze categorias -, transformou-se, no DSM-V, em duas classes diagnósticas com quinze categorias descritas, das quais nove são novas.

A terceira e última análise oriunda do Quadro 1 aborda as alterações relacionadas à infância e à adolescência. A classe diagnóstica, presente no DSM-IV, denominada de Transtornos Geralmente Diagnosticados Pela Primeira Vez na Infância ou Adolescência, foi excluída do DSM-V. Assim, as categorias de transtornos que a preenchiam passaram por exclusões, deslocamentos e alterações para serem abarcadas na nova edição do manual. A primeira alteração concerne ao nome da classe diagnóstica que passa a ser considerada sob a nomenclatura de Transtornos do Neurodesenvolvimento. Além disso, uma mudança bastante marcante foi a exclusão da Deficiência Mental do DSM-V, que passa a não ser considerada como um transtorno.

Por sua vez, a categoria de Perturbações Globais do Desenvolvimento, pertencente à classe diagnóstica de Transtornos Geralmente Diagnosticados Pela Primeira Vez na Infância ou Adolescência do DSM-IV, que incluía o Autismo, o Transtorno Desintegrativo da Infância e as Síndromes de Asperger e Rett, foi condensada para uma única categoria diagnóstica no DSM-V: Transtornos do Espectro Autista.
No que se refere à categoria de Perturbações Disruptivas do Comportamento e de Déficit de Atenção, presente no DSM-IV, ela passa a ser nomeada no DSM-V como Transtornos de Déficit de Atenção/Hiperatividade TDAH. Além disso, no novo DSM a categoria de Perturbações da Alimentação e do Comportamento Alimentar da Primeira Infância ou do Início da Segunda Infância foi excluída, assim como a de Perturbações da Eliminação e Outras Perturbações da Primeira e Segunda Infâncias.

As categorias de Perturbações das Aptidões Motoras e Perturbações de Tique presentes no DSM-IV, na classe de Transtornos Geralmente Diagnosticados Pela Primeira Vez na Infância ou Adolescência, foram deslocadas para uma nova categoria diagnóstica no DSM-V, denominada Transtornos Motores. Ressaltam-se ainda duas novas categorias que foram acrescentadas, no DSM-V, à classe de Transtornos do Neurodesenvolvimento: Deficiências Intelectuais e Outros Transtornos do Neurodesenvolvimento. Assim, fica constatado que as alterações relativas à infância e à adolescência apresentaram, no DSM-IV, sete deslocamentos de categorias e treze exclusões, passando a ser apresentadas, no DSM-V, sob o nome de Transtornos do Neurodesenvolvimento.

Ressalta-se ainda, como pondera Frances (2015), a importância de se manter a atenção para os sinais claros de um possível modismo de "transtorno bipolar infantil", visto que nas últimas duas décadas verificou-se um aumento considerável de psicodiagnósticos de crianças e adolescentes. Com efeito, esta tendência pode ocasionar um mau uso (muitas vezes em massa) de psicofármacos, sobretudo dos estabilizadores do humor, capazes, a longo prazo, de promover maiores adversidades à saúde, tais como diabetes, obesidade, cardiopatia, além de prejuízos psíquicos e sociais.

\section{Tecendo algumas considerações}

Constata-se que os avanços e detalhamentos das descrições psicodiagnósticas do DSM-V e o aumento de classes e categorias diagnósticas parecem influenciar a expansão das indústrias farmacêuticas (ou seu inverso?), que se tornaram as novas detentoras do poder controlador do sofrimento psíquico da população, do mal-estar da sociedade e da veiculação midiática, que contribui reforçando a promessa da anulação de faculdades propriamente humanas, como o sofrimento.

Dessa forma, o espaço da subjetividade torna-se uma mera tradução de suportes técnicos do cotidiano, que, na atualidade, são expressos pela excessiva classificação diagnóstica, ou seja, nomeação em série do sofrimento psíquico, pelo uso abusivo de psicofármacos e por uma grande necessidade de neutralizar aquilo que faz falar no sujeito (TEODORO, 2019). Cabe aqui tracejar as consequências dessas rotas psicodiagnósticas que, embrenhadas na terapêutica psicofarmacológica, legitimam o apagamento do sujeito. A ausência do que faz falar no sujeito - pathos - tampona a dimensão das incertezas, dos enigmas, do não todo que constitui o humano. O que fica é um vazio preenchido que, muitas vezes, não permite ao sujeito desejar. 
Nesses termos, ao produzir a subjetividade que lhe é própria, a contemporaneidade arrasta consigo o padecimento psíquico na forma de excessos e transbordamentos no lugar do que deveria permanecer vazio. O que ora enseja são questionamentos de um não compreender que nas tramas do sofrimento psíquico abrem as portas para se debater as consequências da patologização e medicalização de condições próprias do humano, como a TPM, a tristeza, os comportamentos enérgicos das crianças e os rebeldes dos adolescentes.

Portanto, acredita-se, em consonância com Dunker e Kyrillos Neto (2011, p. 14), que "a psiquiatria ao se afastar da psicopatologia, reconhecendo nela um território demasiadamente ambíguo do sofrimento, do mal-estar e da significação, com sua polifonia de vozes e narrativas, aproxima-se perigosamente de uma prática mecânica de medicalização de massas". De modo que "sua aspiração à universalidade decai em 'totalidade operacional', bem como sua capacidade para intervir na singularidade da clínica degrada-se em 'generalidade particular"' (DUNKER; KYRILLOS NETO, p. 14, grifos do autor).

Em outros termos, estamos, cada vez mais, diante da face contemporânea da psicopatologia, perpassados por aquilo que o filósofo Jacques Derrida perspicazmente nos alertou quando, ao abordar o termo pharmakon nas tradições filosóficas e literárias da Grécia Clássica, mostrou-nos que aquela palavra designava "ao mesmo tempo remédio e veneno" (DERRIDA, 1997, p. 14), abrindo espaço (pensemos nas pílulas, nos diagnósticos, nas siglas diagnósticas e suas transmutações) para uma "virtude de fascinação, a potência de feitiço que pode ser - alternada ou simultaneamente - benéfica e maléfica".

\section{Informações sobre os autores:}

\section{Alexandre Simões Ribeiro}

\section{iD https://orcid.org/0000-0002-1056-2053}

\section{(9) http://lattes.cnpq.br/2909288020998125}

Psicanalista, graduado em Psicologia pela Universidade Federal de Minas Gerais (1993), com Mestrado (finalizado em 1997) e Doutorado (concluído em 2002), ambos na linha de pesquisa dedicada à Filosofia e Teoria Psicanalítica (UFMG). Dedica suas pesquisas, a partir de Freud e Lacan, à Psicanálise na Contemporaneidade e ao campo da Saúde Mental Coletiva. Atua como professor universitário desde 1993. Desde 2000, é professor da Fundação Educacional de Divinópolis (FUNEDI), absorvida (estadualizada), a partir do final de 2014 pela Universidade do Estado de Minas Gerais (UEMG). Já atuou e atua em diversas outras Instituições de Ensino Superior (graduação e pós-graduação). Na docência, atua no nível da Graduação (Curso de Psicologia, nas cadeiras relativas à Psicanálise, à Psicopatologia e à Saúde Mental/Saúde Coletiva) e na Pós-Graduação (especialização e também foi docente e coordenador de 2 programas de Mestrado: Mestrado em Educação, Cultura e Organizações Sociais, de 2005 a 2010, e Mestrado Profissional em Desenvolvimento Regional, de 2011 a 2017). No primeiro programa de Mestrado citado atuou mais diretamente na Linha de Pesquisa em Saúde Coletiva. Tem experiência em ensino, pesquisa e extensão nas áreas de Psicopatologia e Saúde Mental, com ênfase em Psicanálise. É coordenador do grupo de pesquisa PESC: Plataforma de Estudo e Pesquisa sobre Subjetividade e Contemporaneidade, em atividade desde 2008 (cadastrado no CNPq). Ao final de 2008, lançou o livro 'O litoral d'aporia: uma introdução à psicanálise lacaniana', pela editora Garamond. Ao início de 2009, participou da organização do livro 'Educação, Cultura e Organizações Sociais: ensaios interdisciplinares’ (pela Editora Crisálida). Em 2019, organizou o livro 'Psicanálise e Psicopatologia: olhares contemporâneos`(Editora Blucher). Além destes livros, participa como autor de capítulos em diversos outros livros. É também autor de diversos artigos. Desde 2005 a 2018, foi responsável por funções de gestão acadêmica no âmbito da FUNEDI e no âmbito da UEMG (como Coordenador de Pós-graduação e Coordenador do Curso de Psicologia). Atuou como coordenador do Mestrado em Educação, Cultura e Organizações Sociais e, posteriormente, no Mestrado em Desenvolvimento Regional da FUNEDI/UEMG (conceito3, recomendado pela CAPES). Entre 2017 e 2018 atuou como Coordenador do Núcleo de Extensão da FACED, onde também atuou como docente do Curso de Psicologia. É o idealizador e produtor do Canal Alexandre Simões Psicanalista (www.youtube/c/ AlexandreSimoesPsicanalista), dedicado à transmissão de temas e questões relativos à Psicanálise. Desde 1993, atua como psicanalista em consultório particular, realizando atendimento de pacientes e ministrando cursos e palestras na área. É sócio-proprietário da 'Clínica de Psicanálise e Saúde Mental LTDA'.

\section{Gesianni Amaral Gonçalves \\ iD https://orcid.org/0000-0001-5905-3973 \\ (9) http://lattes.cnpq.br/5464259294427621}

Doutora na área de concentração de Estudos Psicanalíticos, na linha de pesquisa Conceitos Fundamentais em Psicanálise e Investigações no Campo Clínico e Cultura pela Universidade Federal de Minas Gerais (UFMG), possui mestrado em Psicologia pela Pontifícia Universidade Católica de Minas Gerais, especialização em Arte - Educação pela Universidade Estadual de Minas Gerais, atualização em teoria Semiótica pela Pontifícia Universidade Católica de Minas Gerais, atualização em Normalização Bibliográfica pela Universidade Federal de Minas Gerais, graduação em Psicologia pela Universidade Estadual de Minas Gerais. Docente da Universidade do Estado de Minas Gerais/ UEMG (Unidade Divinópolis), atuando no curso de Graduação em Psicologia no qual leciona disciplinas como: Psicologia Hospitalar, Psicologia e Atenção em Saúde, História da Saúde, Psicossomática, Psicoterapia Breve, Atendimento Psicológico Emergencial entre outras. Pesquisadora, orientadora de Trabalho de Conclusão de Curso e supervisora de estágio curricular em Psicologia na área da saúde. Líder do grupo de pesquisa ?Plataforma de Estudo e Pesquisa da Subjetividade na Contemporaneidade-PESC? CNPQUEMG. Coordenadora do curso de Pós-graduação Lato Sensu especialização em Psicanálise e Saúde Mental (desde 2016), docente nos cursos de especialização em Psicanálise e Saúde Mental e especialização em Psicologia do Trânsito. Membro da Comissão Científica de Avaliação de Projetos de Pesquisa e Extensão da UEMG (desde 2015). Atuou como docente na FACED/Divinópolis e na UNA/Divinópolis no curso de Psicologia, compondo o Núcleo Docente Estruturante, atuou como docente na Faculdade Pitágoras/Divinópolis e na PUC Minas/Arcos. Possui experiência em ensino, pesquisa e extensão nas áreas de Psicologia e Saúde Mental, atuando especialmente nos seguintes temas: psicologia da saúde, psicologia clínica e psicologia hospitalar. Atuante nos Grupos de Pesquisa: Subjetividade e Transdisciplinaridade (PUC Minas) e Plataforma de Estudo e Pesquisa da Subjetividade e Contemporaneidade-PESC (UEMG). Campo de pesquisa atual: psicopatologia, sintomas, corporeidade e psicologia da saúde. Experiência profissional em Psicologia Clínica com atendimento individual de adultos, crianças, adolescentes, atendimento familiar e de casal na Clínica de Psicanálise e Saúde Mental, onde realiza também o acolhimento e atendimento psicológico de discentes da UFSJ/Divinópolis (via convênio). Áreas de atuação: psicanálise, psicologia clínica, psicologia da saúde, psicologia hospitalar. 
Elizabeth Fátima Teodoro

(iD) https://orcid.org/0000-0003-0977-7265

(9) http://lattes.cnpq.br/5201570313366152

Psicóloga graduada pela Universidade do Estado de Minas Gerais - UEMG / Divinópolis. Enfermeira graduada pelo Centro Universitário de Formiga - Unifor/MG. Pós-graduada em Gestão em Saúde Mental pela Universidade Cândido Mendes. Mestranda em Psicologia, na linha de pesquisa Fundamentos teóricos e filosóficos da Psicologia, pela Universidade Federal de São João del-Rei - UFSJ.

\section{Suelen Aparecida Batista}

iD https://orcid.org/0000-0003-4016-4686

(9) http://lattes.cnpq.br/8677466378771379

Graduada em Sistemas de Informação pela Fundação Educacional de Oliveira (2006). Pós graduada em Administração de Redes Linux pela Universidade Federal de Lavras - UFLA (2013) . Experiência com Sistemas de Informação, nas áreas operacional, técnica, educacional e de gestão. Atuação como técnica em informática e como assessora de informática na Prefeitura Municipal de Oliveira/MG. Atuação como técnica de implantação, treinamentos, parametrização de sistemas, pela empresa Governança Brasil SA. Atuação como professora em cursos técnicos de informática pelo IFMG e no curso de Sistemas de Informação na Fundação Educacional de Oliveira - FEOL. Atuação como supervisora das turmas de curso técnico em Informática pelo PRONATEC - IFMG/ Bambuí - UR: Oliveira/MG - 2013 a 2015. Aluna matriculada no $5^{\circ}$ período do curso de graduação em Psicologia pela UEMG - Unidade Divinópolis/MG. Atualmente professora no curso de Sistemas de Informação pela Fundação Educacional de Oliveira / MG.

Pedro Henrique Estevão Ferreira

(iD) https://orcid.org/0000-0001-6121-2005

(9) http://lattes.cnpq.br/1689583779274233

Possui graduação em Psicologia pela Universidade do Estado de Minas Gerais - UEMG, Unidade Divinópolis (2018). Tem experiência na área de Psicologia, com ênfase em Psicologia Escolar e Psicologia Clínica.

\section{Contribuições dos autores:}

Todos os autores colaboraram ao longo do processo, desde a elaboração até a revisão final do manuscrito. Os autores aprovaram o manuscrito final para publicação.

\section{Como citar este artigo:}

\section{ABNT}

RIBEIRO, Alexandre Simões et al. Psicopatologia na contemporaneidade: análise comparativa entre o DSM-IV e o DSM-V. Fractal: Revista de Psicologia, Niterói, v. 32, n. 1, p. 4656, jan./abr. 2020. https://doi.org/10.22409/1984-0292/v32i1/5674 APA

Ribeiro, A. S., Gonçalves, G. A., Teodoro, E. F., Batista, S. A., \& Ferreira, P. H. E. (2020, Janeiro/Abril). Psicopatologia na contemporaneidade: análise comparativa entre o DSM-IV e o DSM-V. Fractal: Revista de Psicologia, 32(1), 46-56. doi: https:// doi.org/10.22409/1984-0292/v32i1/5674

\section{Referências}

AGUIAR, Adriano Amaral. A psiquiatria no divã: entre as ciências da vida e a medicalização da existência. Rio de Janeiro: Relume Dumará, 2004.

ALBERTI, Sônia; FIGUEIREDO, Ana Cristina. (Org.). Psicanálise e saúde mental: uma aposta. Rio de Janeiro: Companhia de Freud, 2006.
ÁlVAREZ, José Maria; ESTEBAN, Ramón; SAVAGNAT, François. Fundamentos de psicopatologia psicoanalítica. Madri: Sintesis, 2004.

AMARANTE, Paulo Duarte de Carvalho. O paradigma psiquiátrico. In:__. O homem e a serpente: outras histórias para a loucura e a psiquiatria. Rio de Janeiro: FIOCRUZ, 1996. p. $37-64$

BERCHERIE, Paul. Os fundamentos da clínica: história e estrutura do saber psiquiátrico. Rio de Janeiro: J. Zahar, 1989.

BERRIOS, German E. Classificações em psiquiatria: uma história conceitual. Rev. Psiq. Clín., v. 35, n. 3, p. 113-127, 2008. http://dx.doi.org/10.1590/S0101-60832008000300005

BEZERRA JÚNIOR, Benilton. É preciso repensar o horizonte da reforma psiquiátrica. Ciência \& Saúde Coletiva, v. 16, n. 12, p. 4590-4602, 2011. http://dx.doi.org/10.1590/S141381232011001300007

BRASIL. Agência Nacional de Vigilância Sanitária (ANVISA). Prescrição e consumo de metilfenidato no Brasil: identificando riscos para o monitoramento e controle sanitário. Boletim de Farmacoepidemiologia do Sistema Nacional de Gerenciamento de Produtos Controlados (SNGPC), v. 2, n. 2, jul./dez. 2012. Disponível em: http://www.anvisa.gov.br/sngpc/boletins/2012/ boletim_sngpc_2_2012_corrigido_2.pdf. Acesso em: 27 nov. 2019.

BRASIL. Agência Nacional de Vigilância Sanitária (ANVISA). Núcleo de Assessoramento Econômico em Regulação (NUREM)/Gerência de Avaliação Econômica de Novas Tecnologias (GERAE). Boletim Saúde \& Economia: Transtornos de Ansiedade, ano V, n. 10, p. 1-5, 2013. Disponível em: http://portal.anvisa.gov.br/documents/33884/412285/ Boletim + Sa $53 \% \mathrm{C} 3 \%$ BAde $+\mathrm{e}+$ Economia $+\mathrm{n} \% \mathrm{C} 2 \% \mathrm{BA}+10 /$ a45e002d-df42-4345-a3a2-67bf2451870c. Acesso em: 27 nov. 2019.

CAPONI, Sandra. Classificar e medicar: a gestão biopolítica dos sofrimentos psíquicos. Revista internacional interdisciplinar INTERthesis, Florianópolis, v. 9, n. 2, p. 101-122, jul./dez. 2012. https://doi.org/10.5007/1807-1384.2012v9n2p101

CATANI, Júlia. Uma leitura dos transtornos somatoformes $e$ da histeria segundo a CID, o DSM e a obra freudiana: uma identificação do sofrimento psíquico no campo científico. 210 p. 2014. Dissertação (mestrado em Psicologia) - Universidade de São Paulo, São Paulo, 2014. Disponível em: https://teses. usp.br/teses/disponiveis/47/47133/tde-24032015-155213/ publico/catani_me.pdf. Acesso em: 28 nov. 2019.

COUTO, Daniela Paula do; CASTRO, Júlio Eduardo de. Da higiene mental à higiene química: contribuições para um contraponto entre a criança tomada como objeto pelo higienismo e como sujeito de sua verdade pela psicanálise. Cad. psicanal., Rio de Janeiro, v. 37, n. 32, p. 135-157, jun. 2015. Disponível em: http://pepsic.bvsalud.org/scielo. php?script=sci_arttext\&pid=S1413-62952015000100008\&lng =en\&nrm=iso. Acesso em: 19 dez. 2019.

DALGAlARRONDO, Paulo. Psicopatologia e semiologia dos transtornos mentais. 2 ed. Porto alegre: ARTMED, 2008.

DERRIDA, Jacques. A farmácia de Platão. São Paulo: Iluminuras, 1997. 
DSM-IV-TR. Manual de diagnóstico e estatística de perturbações mentais. 4 ed. rev. Porto Alegre: Artmed, 2002.

DSM-V. Manual diagnóstico e estatístico de transtornos mentais. Porto Alegre: Artmed, 2014.

DUNKER, Cristian Ingo Lenz. Crítica da razão diagnóstica: psicanálise, psicopatologia, DSM. In: KYRILLOS NETO, Fuad; CALAZANS, Roberto (Org.). Psicopatologia em debate: controvérsias sobre os DSMs. Barbacena: EdUEMG, 2012. p. $33-74$

DUNKER, Cristian Ingo Lenz. Questões entre a psicanálise e o DSM. J. Psicanal., São Paulo, v. 47, n. 87, dez., p. 79107, 2014. Disponível em: http://pepsic.bvsalud.org/scielo. php? script=sci_arttext\&pid=S0103-58352014000200006\&lng =pt\&nrm=iso. Acesso em: 18 jun. 2019.

DUNKER, Cristian Ingo Lenz; KYRILLOS NETO, Fuad. A psicopatologia no limiar entre psicanálise e a psiquiatria: estudo comparativo sobre o DSM. Vínculo, v. 8, n. 2, p. 1-15, 2011. Disponível em: Disponível em http://pepsic.bvsalud.org/scielo. php?script=sci_arttext\&pid=S1806-24902011000200002\&lng =pt\&nrm=iso. Acesso em: 12 ago. 2018.

FERNANDES, Márcia Astrês et al. Prevalência dos transtornos de ansiedade como causa de afastamento de trabalhadores. Rev. Bras. Enferm., Brasília, v. 71, supl. 5, p. 2213-2220, 2018. http://dx.doi.org/10.1590/0034-7167-2017-0953

FRANCES, Allen. Transtornos bipolares. In: Fundamentos do diagnóstico psiquiátrico: respondendo às mudanças do Dsm-5. Porto Alegre: Artmed, 2015. p. 49-60.

GIL, Antônio Carlos. Métodos e técnicas de pesquisa social. 6 . ed. São Paulo: Atlas, 2008.

JERUSALINSKY, Alfredo; FENDRIK, Sílvia. Introdução. In: . (Org.). O livro negro da psicopatologia contemporânea São Paulo: Via Lettera, 2011. p. 5-10.

KAMERS, Michele. A fabricação da loucura na infância: psiquiatrização do discurso e medicalização da criança. Estilos clínicos, São Paulo, v. 18, n. 1, p. 153-165, jan./ abr. 2013. Disponível em: http://pepsic.bvsalud.org/scielo. php? script=sci_arttext\&pid=S1415-71282013000100010\&lng =pt\&nrm=iso. Acesso em: 13 nov. 2019.

KYRILLOS NETO, Fuad et al. DSM e psicanálise: uma discussão diagnóstica. Revista da SPAGESP - Sociedade de Psicoterapias Analíticas Grupais do Estado de São Paulo, Ribeirão Preto, v. 12, n. 2, p. 44-55, dez. 2011. Disponível em: $\quad$ http://pepsic.bvsalud.org/scielo.php?script=sci arttext\&pid $=$ S1677-29702011000200006\&lng $=$ pt\&nrm=iso. Acesso em: 22 jan. 2019.

KYRILlOS NETO, Fuad; CALAZANS, Roberto (Org.). Psicopatologia em debate: controvérsias sobre os DSMs. Barbacena: EdUEMG, 2012.

LAKATOS, Eva Maria; MARCONI, Marina de Andrade. Metodologia do trabalho cientifico: procedimentos básicos, pesquisa bibliográfica, projeto e relatório, publicações e trabalhos científicos. 6. ed. São Paulo: Atlas, 2001.

LANNES, Amanda Soares. Uso de antidepressivos na infância e adolescência. 120 p. 2018. Monografia (graduação em farmácia) - Universidade Federal de Juiz de Fora, Juiz de Fora, 2018. Disponível em: http://www.ufjf.br/farmacia/ files/2015/04/TCC-Amanda-Soares-Lannes.pdf. Acesso em: 27 nov. 2019.
LEADER, Darian. Simplesmente bipolar. Rio de Janeiro: J. Zahar, 2015.

LUENGO, Fabiola Colombani. A vigilância punitiva: a postura dos educadores no processo de patologização e medicalização da infância [online]. São Paulo: UNESP/Cultura Acadêmica, 2010. Disponível em: http://books.scielo.org/id/sw26r/pdf/ luengo-9788579830877-04.pdf. Acesso em: 27 nov. 2019.

MAGALHÃES, Maria Cristina Rios (Org.). Psicofarmacologia e Psicanálise. São Paulo: Escuta, 2001.

MARTINHAGO, Fernanda; CAPONI, Sandra. Controvérsias sobre o uso do DSM para diagnósticos de transtornos mentais. Physis, Rio de Janeiro, v. 29, n. 2, p. 1-19, 2019. http://dx.doi. org/10.1590/s0103-73312019290213

MENDES, Eugênio Vilaça. O SUS que temos e o SUS que queremos: uma agenda. Revista Mineira de Saúde Pública, ano 3, n. 4, p. 4-26, jan.-jun., 2004. Disponível em: www.esp. mg.gov.br/wp-content/uploads/2009/07/revista04.pdf. Acesso em: 4 set. 2018 .

MORETTO, Maria Lívia. O sofrimento na nossa cultura do sucesso. TV Boitempo. Youtube. 25 jun. 2015. 2h40min. Disponível em: https://www.youtube.com/ watch?v=nTVuwSGx40c. Acesso em: 8 ago. 2015.

NAÇÕES UNIDAS. OMS registra aumento de casos de depressão em todo o mundo... [online]. 2017. Disponível em: https://nacoesunidas.org/oms-registra-aumento-de-casos-dedepressao-em-todo-o-mundo-no-brasil-sao-115-milhoes-depessoas/. Acesso em: 28 nov. 2019.

RESENDE, Marina Silva de. Transtornos mentais ou psicopatologia da vida cotidiana: a questão diagnóstica na atualidade. 122 p. 2014. Dissertação (Mestrado em Psicologia) - Universidade Federal de São João Del Rei, São João Del Rei, MG, 2014.

ROUDINESCO, Elizabeth. Por que a psicanálise? Rio de Janeiro: J. Zahar, 2000.

SILVA, Mardem Leandro. A conjectura lógica de Jacques Lacan [manuscrito]: a lógica como ciência do real. 403 p. 2019. Tese (Doutorado em Psicologia) - Universidade Federal de Minas Gerais, Belo Horizonte, MG, 2019. Disponível em: https://repositorio.ufmg.br/handle/1843/31074. Acesso em: 10 jan. 2020.

SILVA, Tatiana Oliveira da; IGUTI, Aparecida Mari. Medicamentos psicotrópicos dispensados em unidade básica de saúde em grande município do Estado de São Paulo. Revista Eletrônica Gestão \& Saúde, v. 1, n. 1, ed. esp., p. 1726-1737, mar. 2013. Disponível em: https://periodicos.unb.br/index.php/ rgs/article/view/216. Acesso em: 13 ago. 2018.

SIMÕES, Alexandre. Organicismo, DSM e contemporaneidade: continuidades e novidades. In: SIMÕES, Alexandre; GONÇALVES, Gesianinni(Org.). Psicanálise e psicopatologia: olhares contemporâneos. São Paulo: Blucher, 2019. p. 21-33.

TEODORO, Elizabeth Fátima. DSM-5: um marca(dor) da morçada do pathos no contemporâneo. In: SIMÕES, Alexandre; GONÇALVES, Gesianinni (Org.). Psicanálise e psicopatologia: olhares contemporâneos. São Paulo: Blucher, 2019. p. 135-143.

VIEIRA, Elisabeth Meloni. A medicalização do corpo feminino. Rio de Janeiro: Fiocruz, 2003. 